Article

\title{
A Tale of North and South: Balanced and Sustainable Development of Primary Education in Ningxia, China
}

\author{
Jiali Wan ${ }^{1}{ }^{(1)}$, Yanfang Liu ${ }^{1,2, *}$, Yiyun Chen ${ }^{1, *(1)}$, Jiameng Hu ${ }^{1}$ and Zhengyu Wang ${ }^{1}$ \\ 1 School of Resource and Environmental Sciences, Wuhan University, Wuhan 430079, China; \\ wanjiali_whu@163.com (J.W.); hujiameng@whu.edu.cn (J.H.); wangzhenyu@whu.edu.cn (Z.W.) \\ 2 Key Laboratory of Geographic Information Systems, Ministry of Education, Wuhan University, \\ Wuhan 430079, China \\ * Correspondence: yfliu6106@163.com (Y.L.); chenyy@whu.edu.cn (Y.C.); \\ Tel.: +86-27-6877-8863 (Y.L.); +86-27-6877-8863 (Y.C.)
}

Received: 25 January 2018; Accepted: 19 February 2018; Published: 23 February 2018

\begin{abstract}
Education is the driving force of social development, while regional differences have restricted the balance of educational development. This paper provides a political and geospatial analysis of regional inequality across the province from 1990-2015 under a comparative spatiotemporal conceptual framework. Great differences in terms of the distribution and dynamic changes in primary school were found between southern and the northern Ningxia. The southern region has a large number of primary schools with a sharp reduction in these numbers, especially in recent years, while the north has a small but stable number of schools. Spatial accessibility analyses revealed that due to the imbalance between the south and the north, the spatial accessibility of the southern region is much worse than that of the northern region. Our study found the imbalance in the number and spatial distribution of primary schools in the north and south of Ningxia was formed because of multiple factors of policy, geography, and social-economy. The government has pursued a policy of promoting education fairness. However, neglecting differences between north and south, on the contrary, has brought negative effects to the south, worsened the educational environment, and increased education inequities. Our case study in the Ningxia district demonstrates that this research can provide a practical basis for the formulation of policies to guide the rational planning of primary education in Ningxia and/or other similar areas.
\end{abstract}

Keywords: primary education; regional differences; spatial accessibility; sustainable development

\section{Introduction}

Education plays an important role in the development of both the individual and the society. For individuals, education can enhance their skills and abilities [1,2], affecting employment opportunities [3-5], individual income [6-8], and healthy conditions [9,10]. With respect to society, education has a significant impact, including a reduction of social income inequality [11-13] and an increase in social cohesion, citizenship, and political participation [14-16]. In China, education is regarded as the basis of national development. Chinese leaders often say, 'Education is the foundation of a nation and a symbol of national prosperity'. Primary education, as an important part of compulsory education, has long been elevated to a high status. Since the foundation of the new China, driven by the ambitious goal of 'building a socialist country', and the achievement of full literacy goals, the central government has vigorously focused on the development of primary education. The number of primary schools in China increased considerably from 1950 to 1990. In fact, the number of primary schools and primary school students across the nation rose from 346,800 and 24.39 million in 1949 to 894,000 and 14,328 million in 1981, respectively [17]. 
The Chinese government has enacted a series of laws to guarantee the sustainable development of education. Since the founding of the new China (New China: The People's Republic of China, founded in 1949), the government has taken various steps toward the development of primary education to achieve the goals of universal literacy and primary education popularisation. In 1980, the State Council issued the 'Decision on Several Issues Concerning the Popularization of Primary Education', which clarified the significance of primary education and established a clear ten-year goal to achieve universal primary education in the entire country; it begins with a comprehensive development of primary education after the ten years of the 'Great Proletarian Cultural Revolution'. In 1986, the Chinese government enacted the 'Compulsory Education Law', which, for the first time, defined the importance of compulsory education and proposed the Nearby Enrolment Policy by-law. In 2012, China's central government formally introduced the 'Advice on the norms of school mapping adjustment of rural compulsory education'. The document reaffirms the government's obligation to ensure the enrolment of children living closest to the schools and strictly regulates school merger procedures and behaviour which must be approved by the higher government.

The government has issued a series of laws to ensure the sustainable development of Education. However, rapid economic development and urbanization, regional natural endowment, and human factors have led to unbalanced regional economic development, which has consequently become an increasingly serious problem [18]. The regional economic development differences often lead to the unequal development of education, like a poverty trap [19]. Especially in western China, the level of urbanization is low, economic development is weak, and education development is in a serious imbalance $[20,21]$. With the further expansion of urban, rural, and regional differences, the problem of inequality in education has become increasingly serious [22]. This imbalance in development is not only reflected between provinces [23], at the same time, the gap within the province is also very obvious. Therefore, at the provincial level, the study of the distribution of the differences between primary schools in terms of time and space will have a positive effect on the overall understanding of the state of education development.

This paper is organized as follows. The next section reviews the literature on regional differences in educational development. Then, the study area, data, and methodology are introduced. This is followed by a detailed analysis of the imbalance of primary schools in the north and south regions of Ningxia. A detailed spatial analysis is made to reveal the differential development of the south and north of Ningxia from geographical, economic, and political perspectives. Furthermore, we then explore the inequality in the development of primary education caused by regional differences. Finally, this paper concludes with major findings and policy implications.

\section{Literature Review}

Equalization of education is the key factor in realizing the sustainable development of education. However, there are many factors restricting the equalization of primary education, which have been extensively studied from a variety of perspectives. Fennell studied gender equality in education from a policy perspective [24,25], Hannum and Wang argued that geographic disparity has led to educational inequality in China [12], and Yang proves that the disparity between urban and rural areas is the biggest reason for inequality in education in China [26]. By using panel cointegration techniques, evidence on the effect of regional economic development on education inequality is found [27]. Thomas used the Gini coefficient and the Theil index to study the issue of inequality in education [28]. Some scholars adopt the ArcGIS as a technical tool for the description and analysis of the spatial distribution of educational equality [29]. Setyono used ArcGIS analyses of the scale and service capacity of public service facilities in Indonesia [30], and Cao assessed the service capability of schools to study the impact of spatial distribution and educational equity in Gansu [31]. In China, because of the great differences in social-economic development and geography, regional inequality in education is very serious, however, Yu found a robust non-linear nexus between inequality in educational attainment and economic growth [27]. 
In order to improve education equality among regions and between urban and rural areas, the government proposed the School Consolidation Policy in the mid-1980s. This policy is not unique in China. In the process of urbanization in developed countries, the practice of reducing the number of schools or merging schools is widespread. The aim of the School Consolidation Policy was to promote the balanced development of education and educational quality [32]. However, different scholars have different views of the policy. Coton's findings suggest that smaller schools have lower dropout rates [33]. Lee found that very large or very small schools are often at a disadvantage, but small schools are more conducive to promoting equality in education [34]. In contrast, Conant proposed the theory of scale rationality and reported that only by eliminating small schools can we make effective use of the money spent on schools and provide students with a relatively high quality of education [35]. Beeson stated that the rural economy is depressed and the number of rural students has been reduced; thus, the number of schools should also be reduced by merging small rural schools [36]. In China, most scholars think that the disadvantages of school consolidation outweigh the advantages. School consolidation has led to a serious imbalance in the distribution of educational resources. A large number of repaired teaching buildings have been abandoned in rural areas, while the merged schools have become overcrowded and over sized [37-39]. Moreover, the increase in the cost of attending school has resulted in a heavier burden on family education, including accommodation costs, transportation, fees and some other miscellaneous fees [32]. Due to the increase in the distance to school, students have frequent accidents on their way to school, and such problems are particularly serious in underdeveloped areas $[40,41]$. What is more, the reduction in the number of schools has not only failed to effectively integrate educational resources to allow improvement in teaching quality, but has also led to a large number of educational resources moving to the cities and further increasing the inequality of inter-regional education [42].

Many studies have been conducted on educational inequality in China, but a large amount of them, because of a lack of data, have only focused on qualitative analysis or had a very small research scale (e.g., township or village level). Therefore, the overall situation has not been well reflected. On the basis of introducing the spatial accessibility index into this study, we have analysed the challenges for the sustainable development of primary education in the case of the regional difference between the north and the south of Ningxia. Further, we have reviewed the development of China's primary education policy to explore the large-scale regional differences and to find out how to better achieve the sustainable development of primary education.

\section{Study Area}

Ningxia Hui Autonomous Region (Ningxia for short) lies in the upper reaches of the Yellow River in western China. To outline the Ningxia territory, the terrain is cross shaped, north and south areas are long, west and east areas are short, with a total area of more than $6.64 \mathrm{~km}^{2}$. The topography of Ningxia slants toward the north with an elevation from 1100 to $2000 \mathrm{~m}$. In 2015, Ningxia's gross domestic product (GDP) was Chinese Yuan Renminbi (CNY) 291,177 million and the per capita GDP was CNY 44,015, which was lower than the national average of CNY 50,251. Among China's undeveloped districts, Yinchuan, the capital of Ningxia, accounted for more than half of Ningxia's GDP. Economic development has lagged, and the development has been extremely uneven. The distribution of primary schools in Ningxia's 22 counties is shown in Figure 1. On the basis of the locations of Yanchi County and Haiyuan County, along with the manmade geographical lines, Ningxia is divided into two regions- the north and the south—with obvious regional differences, and the difference in the amount of economic development between the north and the south is huge. The per capita GDP in the northern counties was higher than that of the south, and eight counties in the southern region were listed as poor counties in China. Poor counties are a standard set by the state to help poor areas. The delineation of the national poverty-stricken counties is based on the average annual net income, mainly concentrated in the central and western regions. The current total number of poor counties in China is 592. The Ningxia area was utilized for this case study. 


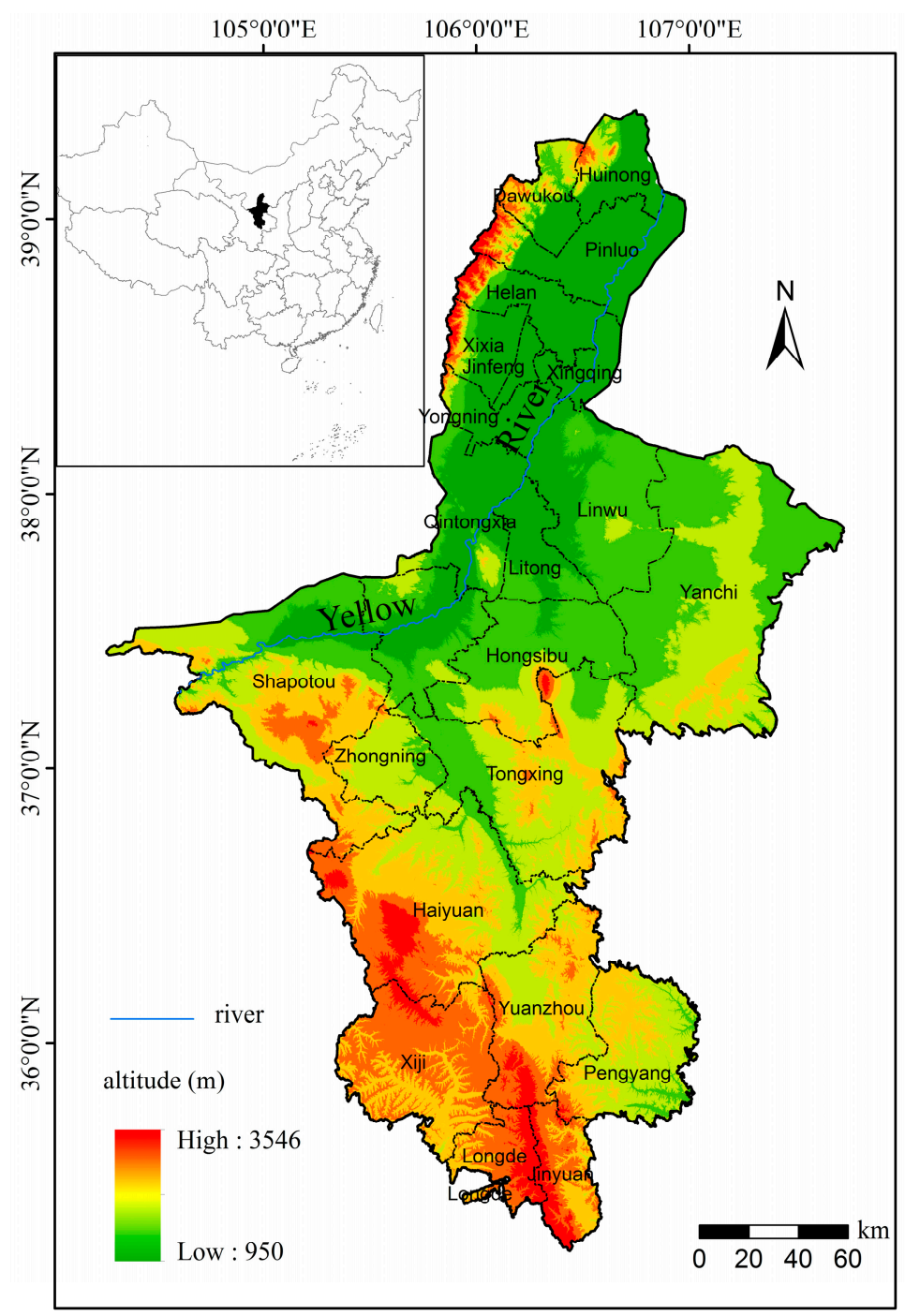

Figure 1. Study area.

\section{Methodology}

In this study, the Geographic Information System (GIS) was used for obtaining the settlement, transportation, school, and other data. Charts and spatial statistics of the distribution of schools, residential and traffic road network data for different residential education service equalisation levels, spatial accessibility analysis, social and economic data analysis, qualitative analysis, and a quantitative analysis of the distribution of the educational facilities were used for highlighting the contradiction between the number of primary schools and sustainable development.

Spatial accessibility was analysed using two sets of indicators. One was the distance used to calculate the average distance and the longest distance from each residential location in the district to the nearest primary school. The second indicator was the commuting time. First, buffers were built using the distance from the road network. Then, buffers were classified according to the commute time, for example, $10 \mathrm{~m}, 20 \mathrm{~m}$, and $30 \mathrm{~m}$, respectively. The commute time was calculated according to the road grade. Different road grades would allow different speeds. The speed of the fast city road design with all kinds of channels, city trunk roads or city roads, city branch, and rural roads is $70 \mathrm{~km} / \mathrm{h}$ or $50 \mathrm{~km} / \mathrm{h}, 40 \mathrm{~km} / \mathrm{h}, 30 \mathrm{~km} / \mathrm{h}$, and $40 \mathrm{~km} / \mathrm{h}$, respectively.

The Theil index was introduced as an indicator of the educational balance. The Theil index was proposed in 1961 [43], and since then, it has been widely applied to the analysis of equilibrium in various fields, such as regional development disparity [44], spatial disparity in energy efficiency [45], 
health disparities [46], and regional income inequality [47]. Many scholars have also applied the Theil index to the balanced development of education [48-51]. We calculated the Theil index of inequality using the following standard formula:

$$
T=\frac{1}{n} \sum_{i=1}^{n} \frac{y_{i}}{\bar{y}} \log \left(\frac{y_{i}}{\bar{y}}\right)
$$

where $T$ is the overall Theil index, $y_{i}$ is the school per capita number of students of the county, $n$ is the total number of counties, and $\bar{y}$ is the average school per capita number of students of all $n$ counties.

\section{Results and Discussion}

This section is divided by subheadings. It will provide a concise and precise description of the experimental results, their interpretation, as well as the experimental conclusions that can be drawn.

\subsection{Imbalance of the Distribution of Primary Schools in the North and South Regions of Ningxia}

Due to the dual influence of economic and geographic factors, the number of primary schools in the north and the south is very different. Further, these differences are in stark contrast to the degree of economic development. As shown in Figure 2, in the southern region, the number of primary school facilities is nearly $3 / 4$ of the total for all of Ningxia, and these schools are more widely distributed. In contrast, in the northern region, there are fewer primary schools, and their distribution is very concentrated; basically, they are concentrated in the central administrative region.

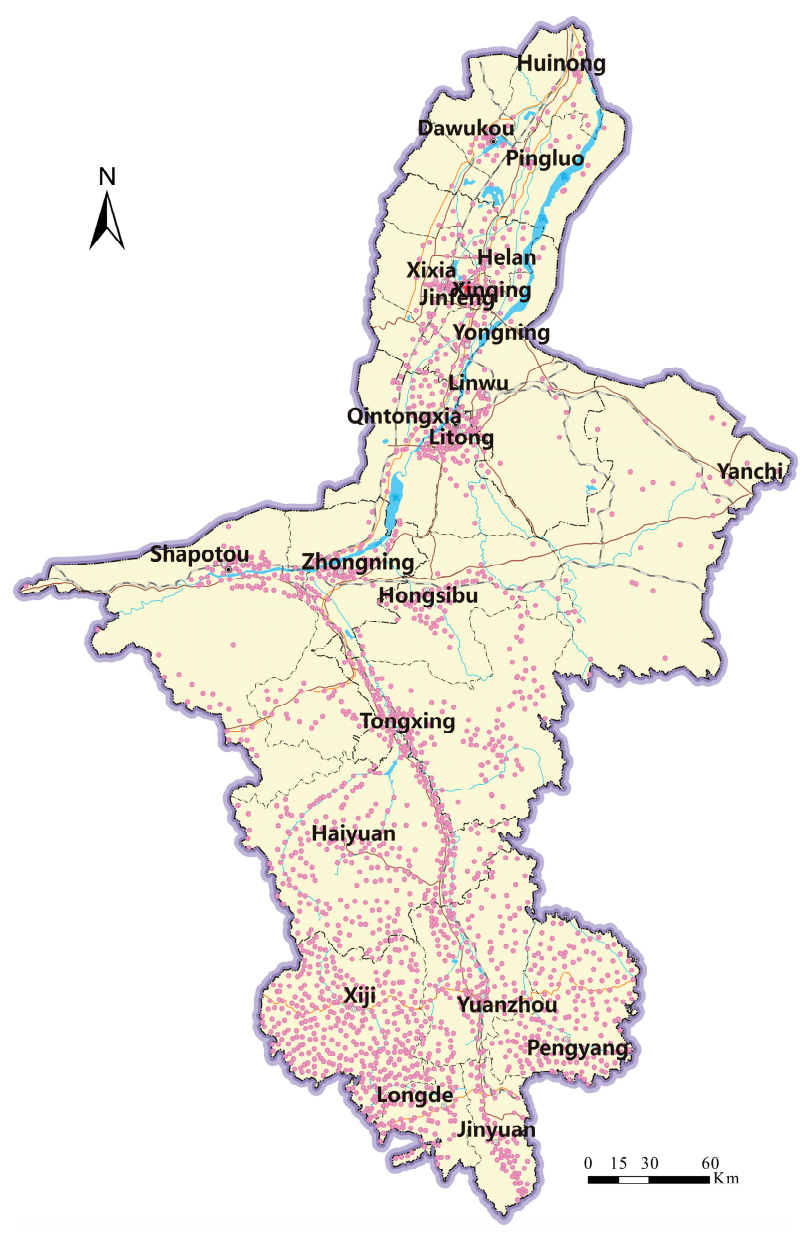

Figure 2. Spatial distribution of primary school in Ningxia. 
The number of primary schools is an important indicator of the fairness of education, which implies that in this region, with a better embodiment of regional public services, every school-aged child's right to nearby enrolment can be guaranteed. However, the number of primary schools in the north and south regions of Ningxia differ significantly; in the well-developed northern region, the number of primary schools is significantly lower than that in the southern region where economic development lags. As shown in Figure 3, in Ningxia, the number of primary schools did not show a positive correlation with the GDP or the population, but showed an increasing trend from the north to the south, forming a considerable contrast between the north and the south.
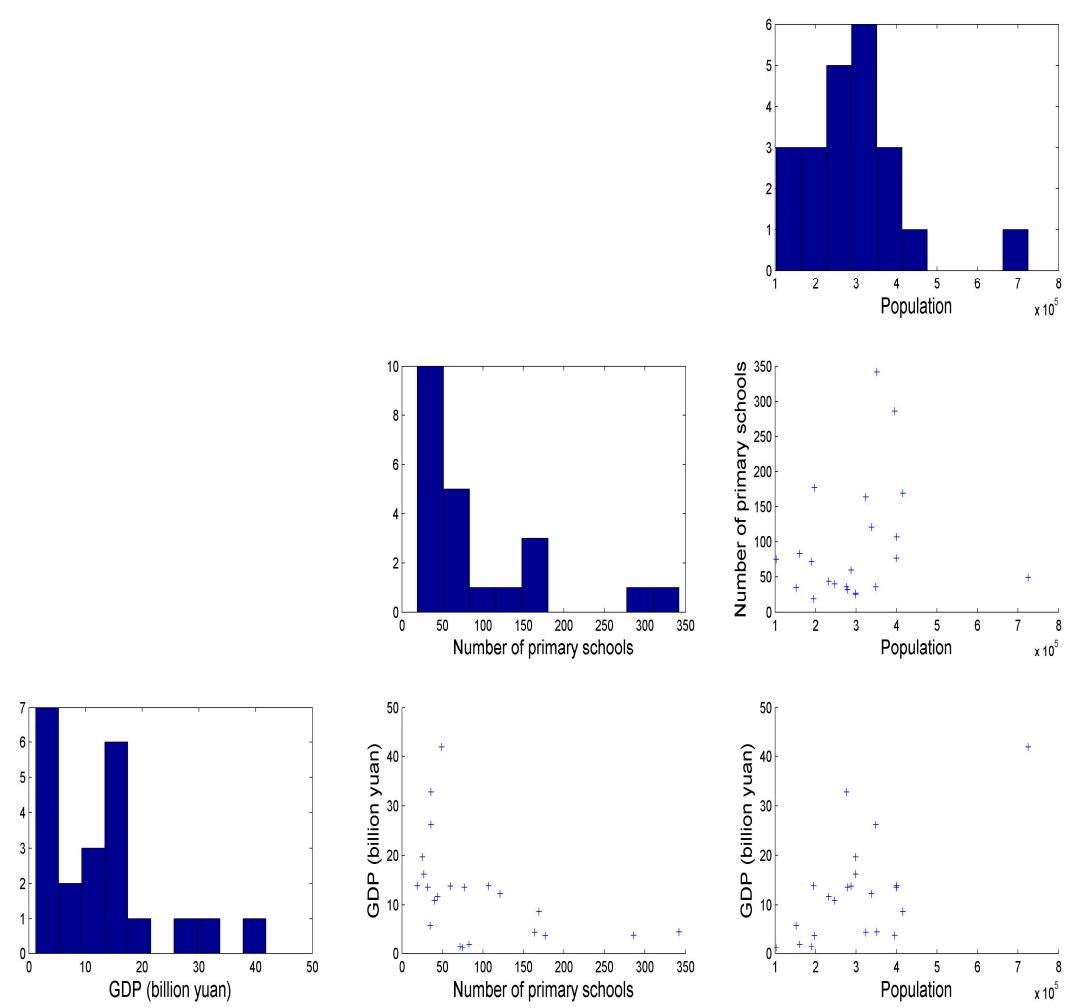

Figure 3. The relationship among the number of primary schools, gross domestic product (GDP), and population.

The reason for this contradiction is multifaceted and includes geographical, socioeconomic, and political factors. The same educational policy under different socioeconomic and geographical conditions may have considerably different results. The national policy orientation results in a considerable difference in the number of primary schools in the north and the south. The existence of a large number of primary schools is a result of the 'one village, one school' policy. Since the founding of the new China, the Chinese government has made a considerable effort to ensure primary education for all in order to eliminate illiteracy. At that time, the primary education policy promoted by the Chinese government was to set up a primary school in each village. In the context of this rationale, China's 'one village, one school' policy virtually covers all of the rural areas in China. In fact, a large number of primary schools have been established in the vast rural areas of China as a result of this policy.

However, differences in the geographical terrain have resulted in an uneven distribution of primary schools in the north and south regions. From a geographical point of view, Ningxia can be roughly divided into the northern plains and the southern mountains; the elevation from the north to the south exhibits an increasing trend, and the average elevation in the northern region is 1000-1400 m and that in the south is $1400-2300 \mathrm{~m}$ (see Figure 1). Ningxia's northern region is flat, and the terrain slopes gently; therefore, the distribution of the residential areas is more concentrated. In contrast, the southern part of Ningxia is a mountainous area with a high altitude and complex geology and 
topography; therefore, the distribution of the settlements is more dispersed and characterised by small size and a large number. The differences in topography have also led to differences of transportation. Under the same commuting time, the service scope of the schools is also different due to the difference of terrain in the north and south. The more complex the terrain, the smaller the school's service range. Therefore, with respect to the policy of 'one village, one school', the number of elementary schools in the northern part is relatively small, and, as there are more residents in the southern part, the number of primary schools in the south is obviously more than that in the north. In addition, the difference in socioeconomic development has led to large differences in the number of primary schools in the northern and southern parts of Ningxia, which is reflected in the considerable differences in the level of urbanization.

The differences of the urbanization rate in the north and the south of Ningxia are/could be another reason for the unequal distribution of schools. In Ningxia, the urbanization rate in the north and the south is significantly different: in the northern county it is high and in the southern county it is low, as shown in Figure 4. Ningxia's northern counties have an urbanisation rate of more than $40 \%$, with the provincial capital Yinchuan City (including Jinfeng, Xixia, and Xingqing) and its surrounding counties, such as Huinong and Dawukou, accounting for more than $80 \%$ of the abovementioned rate. In contrast, the southern counties have an urbanization rate of less than $40 \%$, in fact, the rate is approximately $25 \%$. This implies that most of the southern part of Ningxia is rural. Thus, to achieve the goal of 'one village, one school', the southern part of Ningxia has intently focused on the development of its rural primary education. Further, the government has sufficient financial resources to improve the quality of primary education and consider primary school development as part of the sustainable development of the region. In contrast, the economic development of the southern region is poor, but the number of primary schools is large. Thus, the government does not have sufficient financial resources to improve the quality of primary education and cannot even meet the basic daily expenditure of each school [21].

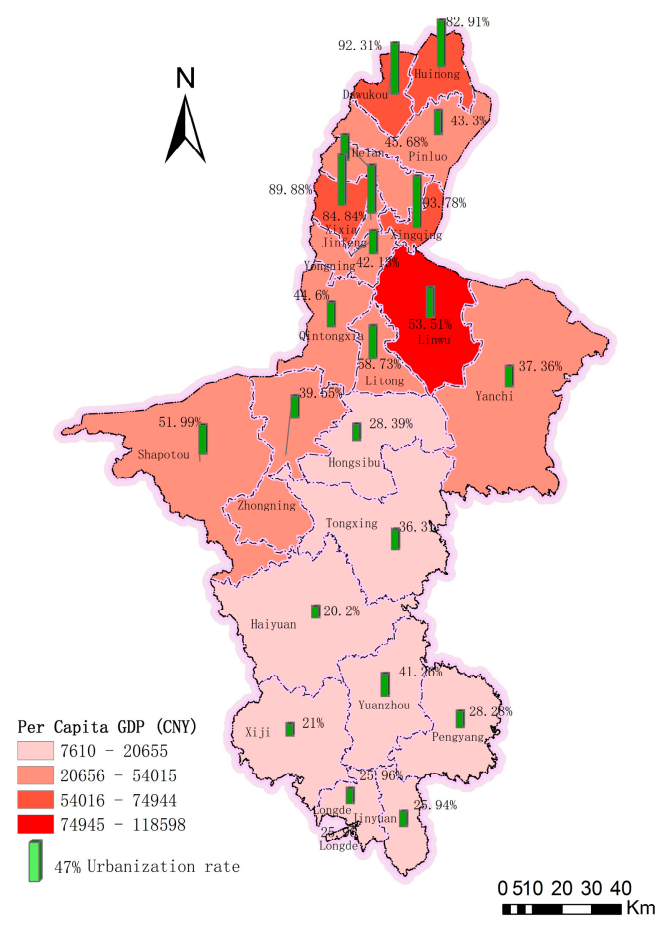

Figure 4. Per capita GDP and urbanization rate.

In China, primary school education is part of compulsory education, and in accordance with the law, all the expenses for students to receive education should be borne by the state. Therefore, the development of primary education must be supported by the government's fiscal revenue. However, 
after 2000, the central government transferred the expenditure of primary education to the local and county governments. In other words, local primary education expenses had to be supported through the county government's revenue. Because of the contradiction between economic development and the number of primary schools in the southern and northern regions of Ningxia, the local governments in the southern regions could not support the fiscal burden of its large number of primary schools. So, the government had to either decrease the number of primary schools, or reduce the funding for each school. Moreover, it introduced numerous fees on rural households in order to generate income to ease the pressure of the education costs [52-54]. This resulted in some students receiving poor-quality primary education and a significantly high number of dropouts, which made the elementary education development unbalanced and unsustainable. This has created a huge imbalance between the financial power and the administrative power of the government, resulting in the vicious trend of 'the poorer, the harder; the harder, and the poorer'. Free primary education in poor areas in China generally provides low education quality due to the poor local fiscal revenue, which results in low enrolments of poor children in higher education $[55,56]$. What is more, poor education leads to poor labour market outcomes, which again reproduces poor education [19].

\subsection{Changes in the Number of Primary Schools in the North and the South}

In Ningxia, the number of primary schools changed tremendously between 1990 and 2015, (see Figure 5). A large number of primary schools were shut down; the reduction in the southern region was considerably larger than that in the northern region. With eight poor counties in the southern region, the number of primary schools in this region decreased by more than 100 . The largest reductions were in three counties of the southern region: a decrease of 475 in Yanchi County, of 423 in Tongxin County, and of 359 in Haiyuan County. The change in Ningxia is only a microcosm of the whole country (see Figure 6). The number of primary schools in China has decreased, and the rate of decrease was extremely rapid around 2000. Compared with the national rate of reduction, the overall rate for Ningxia is slightly lower.

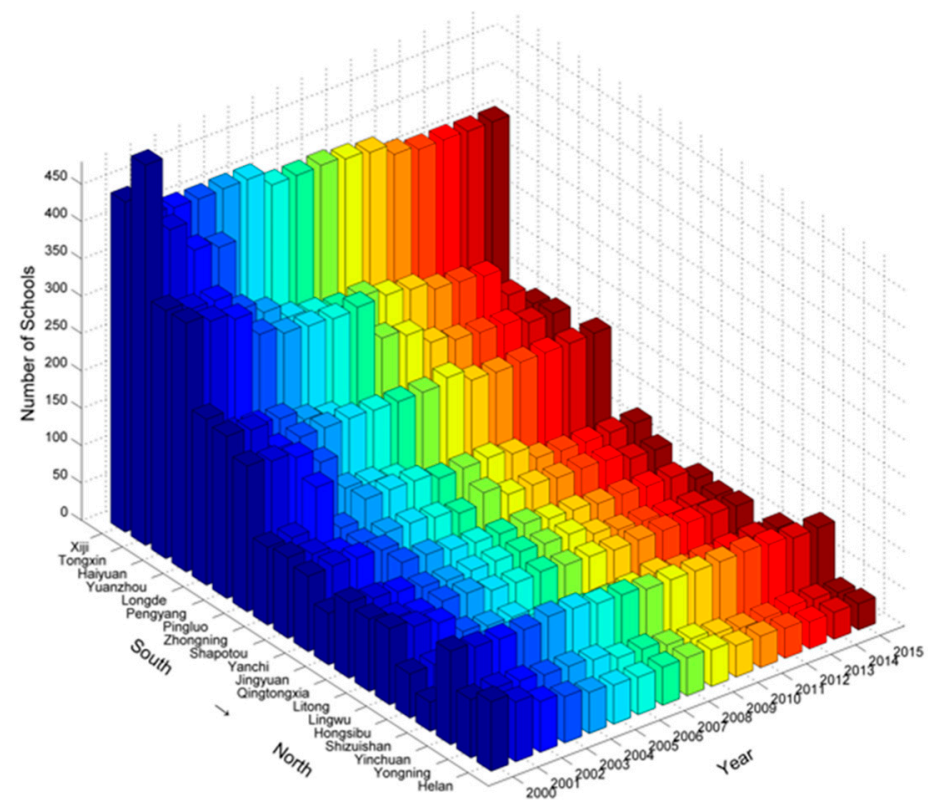

Figure 5. Temporal changes in the number of primary schools from 2000 to 2015. 


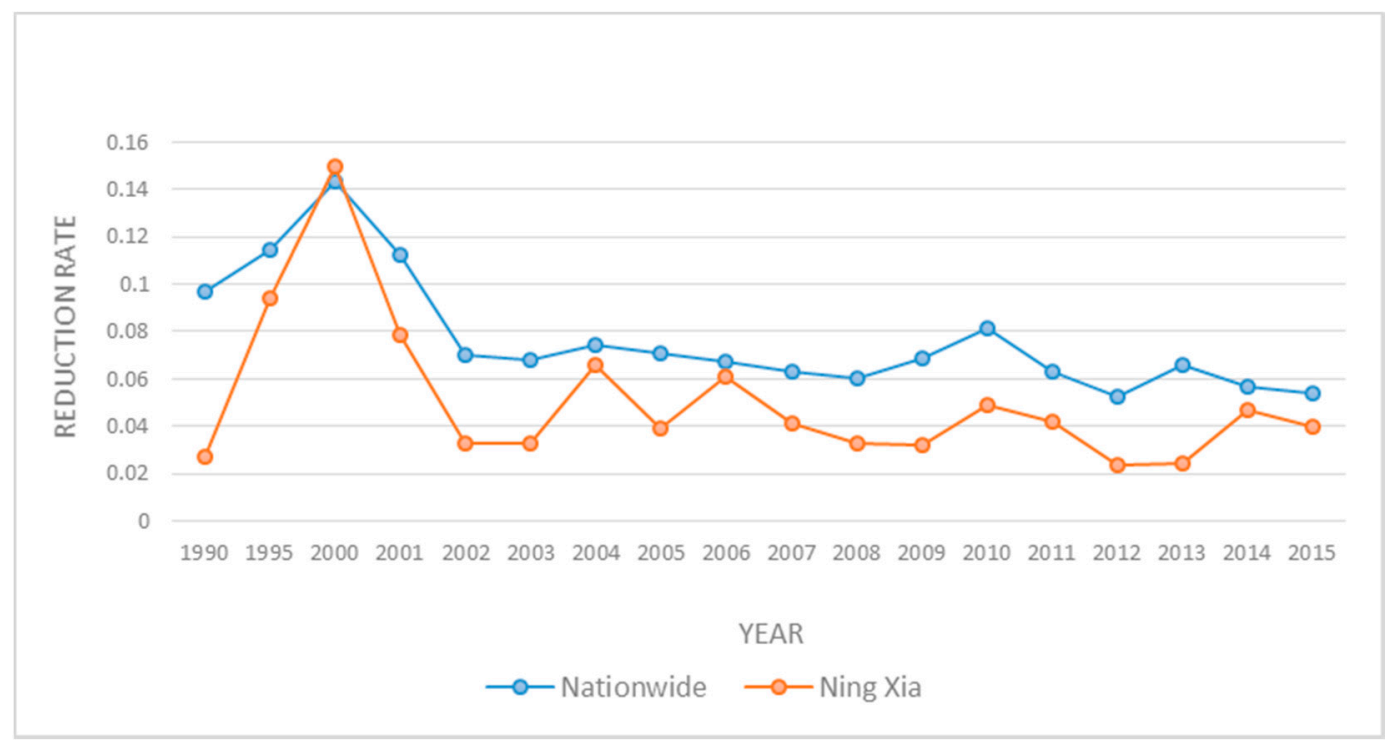

Figure 6. The reduction rate of the number of primary schools.

There are several reasons for the large-scale reduction in the number of primary schools concentrated in the poor and undeveloped areas of southern Ningxia. First, since the founding of the new China, the state has called for vigorous efforts for the development of primary education and the elimination of illiteracy $[57,58]$. The large-scale development of primary school education is a political movement akin to a revolution [57]; in fact, the state and local governments have not considered the regional balance and population trends. As a result of the one-child policy [58] and the relocation of a large number of peasants to the cities $[59,60]$, the number of rural children has dropped sharply; this has led to a large number of schools that are unused and a serious waste of educational resources.

Secondly, after the reform of the tax sharing system in 1994, the central government devolved a large number of powers to the local governments, which implied that the local governments had to shoulder more responsibilities [61,62]. In 2000, the central government issued a series of rules and regulations, leading to the county government being responsible for the funding of elementary education in its district. However, in China, the greater the number of rural areas, the less developed is the economy, and the lower the local financial revenue, the higher the number of primary schools. As in Ningxia, a large number of primary schools were concentrated in the economically undeveloped areas of the south. A large number of schools and a serious shortage of local fiscal revenue inevitably resulted in the relative shortage and backwardness of the hardware and software facilities of the schools. In this context, the local governments of economically undeveloped areas, in order to cope with the considerable financial pressure and solve this dilemma, had to quickly and effectively respond to the new regulations.

Thirdly, with economic development and the increased educational consciousness, the views of farmers on education have also changed. They not only hope to receive an education, but also hope to receive good-quality education. As the rural primary school education, because of a lack of funds, lack of qualified teachers, and the overall education atmosphere, is undeveloped, it is difficult for many rural parents to send their children to schools that provide good-quality education. This has further exacerbated the problems of low school enrolment and wastage of educational resources in schools.

From the perspective of the number of primary schools, school combination policy has played a positive role in achieving an appropriate number of primary schools in a sustainable manner by reducing the number of primary schools in the country to adapt to the changes in the number of students at school. The Theil index was used to measure the balance of primary schools in all counties in Ningxia from 1990 to 2015 (see Figure 7). The results show that the maximum Theil index was 0.206, 
the lowest was 0.108 , and the overall variation trend of the Theil index showed a decrease from high to low. Before the large reduction in the number of primary schools in the south, the Theil index was significantly higher, indicating a considerably uneven distribution of the number and population of primary schools in the southern region (see Figure 6). The overall trend, after 2000, with the decline in the number of schools in the south, showed that the problem of the uneven spatial distribution of the primary schools in the southern and the northern regions of Ningxia has indeed improved. The Theil index showed a marked decline and finally maintained a relatively stable value. This implies that the decrease in the number of primary schools had a positive effect on the development of education in Ningxia.

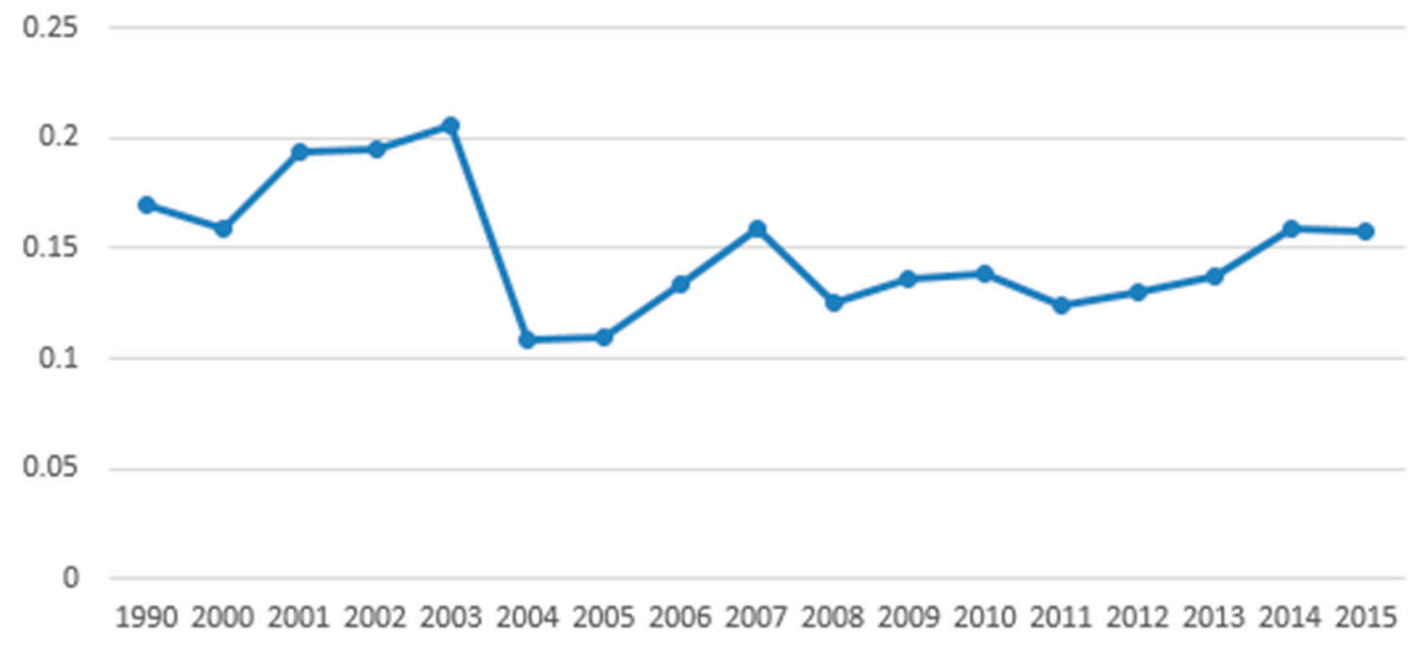

Figure 7. Theil index of the number of people per school.

Although the decrease in the number of primary schools was inevitable, when blindly done, the reduction did not fully take into account the rationale of the spatial distribution of the primary schools. This led to an uneven distribution, causing serious problems for school-aged children to get to the schools. Ningxia is facing such a problem. After a massive reduction in the number of primary schools, primary school education is a problem; in particular in the southern region. In some remote areas, the accessibility of primary school education is very poor, which leads to the problem of a considerable distance between students, schools, and families and, therefore, students find it difficult to go to school.

\subsection{Differences in the Spatial Accessibility of Primary Schools}

The reduction of the number of primary schools has alleviated the financial pressure in the southern region to a certain extent, and promoted a relative balance between the number of students and the number of schools, but it has ignored the consequent problems of spatial accessibility. The substantial reduction of schools in southern Ningxia has led to a conflict between the accessibility of primary schools and the geography of the south. An analysis of the time accessibility and distance accessibility of the primary schools in the Ningxia district revealed that the accessibility to primary schools in southern Ningxia is relatively poor, particularly in counties with a reduction in the number of these schools; these results are particularly significant.

From the maximum accessibility distance and the average-accessibility distance index, we can find that the index of the maximum-accessibility distance between northern and southern is different (see Figure 8). The maximum distance appears in Pengyang County, which is $10,530 \mathrm{~m}$. This means that students in these areas have a long journey to school. This suggests that the reduction of the number of primary schools will considerably reduce the accessibility of education in the poor southern region. This also shows that the simultaneous rapid reduction in the number of primary schools has led to the problem of poor spatial accessibility, which is extremely detrimental to the sustainable 
development of education in the region. For the southern region, the index is much higher than for the northern region with the maximum distance varying greatly; the maximum and minimum gap was $41,336 \mathrm{~m}$, and the number of schools decreased fastest in Pengyang and Yanchi, where the distance was $38,693 \mathrm{~m}$ and $32,425 \mathrm{~m}$, respectively. This was $10,000 \mathrm{~m}$ higher than the northern area, indicating poor accessibility to primary schools of these areas and an extremely unreasonable distribution.
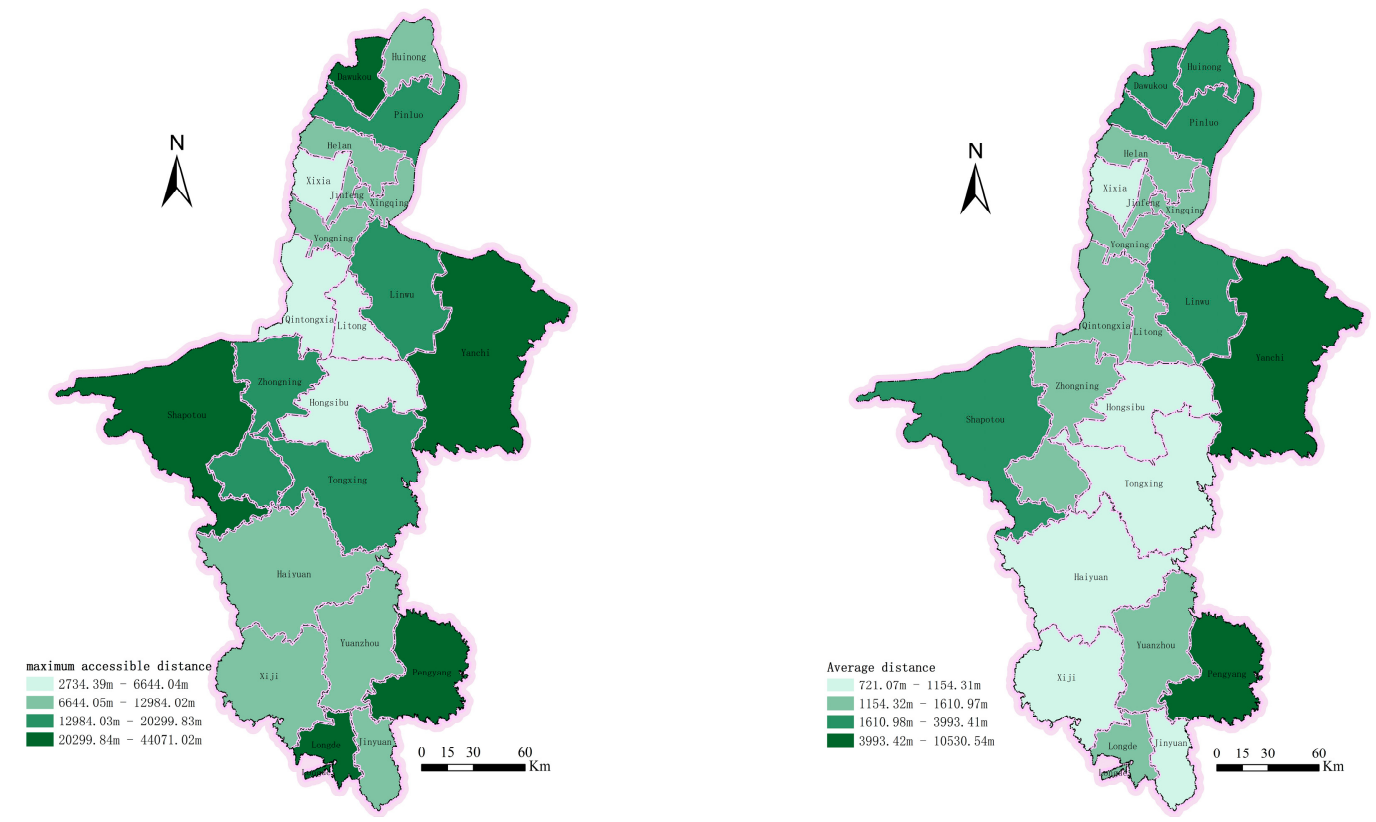

Figure 8. Primary school spatial accessibility analysis map.

The spatial accessibility of primary schools is affected by the number and distribution of these schools, which is an important indicator for evaluating the effectiveness of primary education. The spatial accessibility of primary schools in the south and the north reflects the uneven development of primary education in Ningxia. Spatial accessibility can indicate whether the distribution of primary schools in a region is good and whether it can meet the demands of the residents with respect to educational services. Good spatial accessibility denotes a rational distribution of primary school education in the region and balanced development. In contrast, poor spatial accessibility shows that the distribution of educational facilities in the region is irrational and cannot meet the demands of the residents with respect to the educational services.

The results showed that the time accessibility of the southern region was considerably lower than that of the northern region (see Figure 9). When the service area of the primary school was set to $10 \mathrm{~min}$, the results showed that the northern region had more than $90 \%$ coverage, while the southern region had approximately $50-70 \%$ coverage. Yanchi County had the lowest coverage rate of only $55 \%$. These counties with a low coverage were the poor counties where there was a significant reduction in the number of primary schools. The coverage of the educational facilities in the southern region increased slowly with time. However, even at $30 \mathrm{~min}$, the southern region of Longde and Haiyuan exhibited a coverage rate of only $85 \%$. 


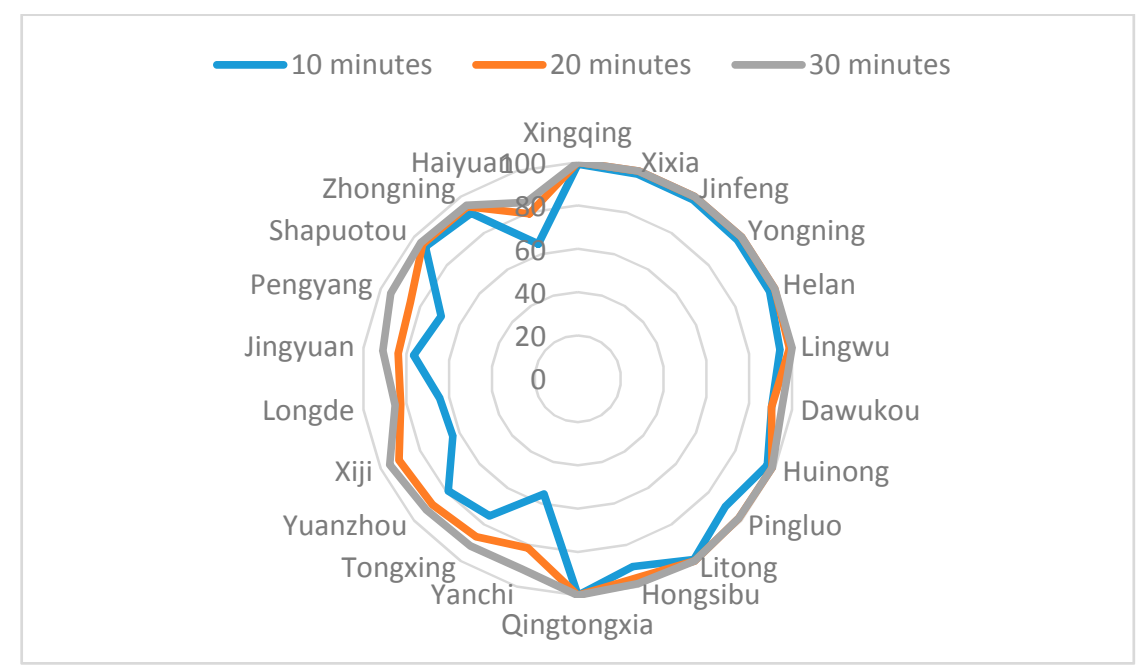

Figure 9. Analysis of the differences in the accessibility of primary schools.

From a comprehensive analysis of the data of spatial and time accessibility, the accessibility of primary schools is poor in southern Ningxia. Local governments blindly reduced the number of primary schools, resulting in a large number of students having an increase in the distance they have to travel to school. Primary school education resourcing has had a very bad impact on fairness in poor and remote areas. Southern school-age children receive a basic education in primary school, which further increases inequality among primary schools in different regions.

\subsection{Balanced and Sustainable Development of Primary Education in the North and the South}

There is a considerable difference between the geographic factors and the economic development rate of north and south Ningxia. In reality, there are various contradictions in realising such sustainable development. The decrease in enrolments and the wastage of educational resources has led to conflicts between the number of students and the number of schools. With the massive annexation of southern primary schools, the balance of schools in the north and the south has been improved and the problem of financial pressure and wastage of educational resources in the south has been resolved. However, because of the complex topography and scattered settlements in the southern region, the decline in the accessibility of schools has resulted in a decrease in school availability, with the students deprived of their right to enrol in the closest primary school. This has in turn led to a conflict between the number of primary schools and their spatial accessibility. Therefore, for the sustainable development of education, we must take into account regional differences, and avoid the implementation of blind policies that may restrict the development of education. Based on the empirical data of Ningxia, we can effectively ensure the sustainable development of education by implementing government policies according to the local conditions.

Firstly, the rational withdrawal of the southern primary schools will promote a healthy and sustainable development of education. The number of primary schools must be decided considering school attendance and the local economic conditions. An excessive number of unreasonable schools will directly lead to a pressure on local finances and a wastage of educational resources. Without adequate financial support, local primary education cannot be well developed and effective education cannot be guaranteed, which will inevitably lead to considerable differences in the quality of education among regions. In the southern region, economic development is slow and the fiscal revenue is low. The local governments do not have enough to invest in education. A considerably large number of primary schools will inevitably lead to financial difficulties. This will directly limit the improvement of the quality of education in primary schools. At the same time, the immense mismatch between the number of enrolled students and the number of schools has led to a wastage of educational resources. 
Under such circumstances, only by effectively integrating educational resources, coordinating the number of schools and the number of students, and allocating educational resources reasonably, can we promote the improvement of education in southern Ningxia to achieve sustainable development?

Secondly, the spatial distribution of primary schools should be reasonably planned to meet the students' right to enrol at the closest school under different natural and social conditions. From the investigation, we found that the local government's blind merging of schools has led to a spatial accessibility problem for poor students. In southern Ningxia, the number of primary schools has been reduced, and more than half of this reduction was in five counties. The results of the spatial accessibility study showed that the accessibility in the southern region is poor, particularly in counties with significant reductions, and the primary school coverage is very low.

Because of the features of the terrain in the southern part of Ningxia, the layout of the settlements shows the characteristics of small size, large quantity, and scattered distribution. The inevitable result of a large number of reductions in the number of schools is the deterioration of the spatial accessibility. From the viewpoint of data, the number of primary schools in the southern region is still large. However, in spite of this large number of schools, the spatial accessibility in the southern region is considerably worse than that in the northern region. Therefore, the spatial layout of primary schools should take into account the terrain factors for an effective integration of educational resources.

\section{Conclusions}

Primary school education is the most basic and most important part of compulsory education. The legal connotation of compulsory education is that it is a right given by law, but also an obligation that the people must go to school. As an obligation, you must complete the legal responsibility to accept education when you are school-aged. As a right, the country must provide the physical facilities, arrangements, and guarantee the quality of the teaching.

As the most basic and important part of the development of China's education, primary education must be the most reasonable and balanced guarantee. In particular, in undeveloped poverty-stricken areas, education is the most important condition for the development of individuals and society. How can it be effective? Balanced implementation of primary education must be fair to provide each school-aged child with the basic education facilities. Primary education faces a double conflict. On the one hand, the large number of primary schools leads to local financial difficulties. Various educational facilities cannot be guaranteed. Small scale and poor development have become a common phenomenon. Primary education development is limited. On the other hand, a reduction in primary schools will lead to poor accessibility with students not guaranteed entry to a school nearby. Therefore, the planning of the distribution of schools in the case of limited local finance is a problem that local governments must seriously attempt to resolve.

Based on the analysis of the number of primary schools and of spatial reachability, in this study, we conducted thorough research on primary education in Ningxia and found that the imbalance of education was caused by the decrease in the number of educational facilities.

Therefore, we make the following recommendations: (1) Reasonable spatial layout-remote and poor areas should have a relatively concentrated distribution of primary schools to enable students to get to school easily; and (2) Increased financial support in all poor areas of education development-the local and the central governments must increase the financial support for primary schools, in the form of transfer payments and special funds.

Acknowledgments: This work was financially supported by the National Key Research and Development Program (Grant No.: 2017YFB0503505) and National Natural Science Foundation (No. 41771432).

Author Contributions: Jiali Wan, Yanfang Liu, and Yiyun Chen conceived and designed the experiments; Jiali Wan and Jiameng Hu performed the experiments; Jiali Wan analyzed the data; Yanfang Liu, Zhengyu Wang helped in language correction; Jiali Wan wrote the paper.

Conflicts of Interest: The authors declare no conflict of interest. 


\section{References}

1. Autor, D.H. Skills, education, and the rise of earnings inequality among the "other 99 percent". Science 2014, 344, 843-851. [CrossRef] [PubMed]

2. Glewwe, P. Schools and skills in developing countries: Education policies and socioeconomic outcomes. J. Econ. Lit. 2002, 40, 436-482. [CrossRef]

3. Robinson, P.B.; Sexton, E.A. The effect of education and experience on self-employment success. J. Bus. Ventur. 1994, 9, 141-156. [CrossRef]

4. Carnoy, M. The great work dilemma: Education, employment, and wages in the new global economy. Econ. Educ. Rev. 1997, 16, 247-254. [CrossRef]

5. Van Ham, M. Education, training and employment dynamics. Transitional labour markets in the European Union. Econ. Educ. Rev. 2003, 22, 646-647. [CrossRef]

6. Seeman, T.; Merkin, S.S.; Crimmins, E.; Koretz, B.; Charette, S.; Karlamangla, A. Education, income and ethnic differences in cumulative biological risk profiles in a national sample of US adults: Nhanes III (1988-1994). Soc. Sci. Med. 2008, 66, 72-87. [CrossRef] [PubMed]

7. Griliches, Z.; Mason, W.M. Education, income, and ability. J. Political Econ. 1972, 80, S74-S103. [CrossRef]

8. Yang, D.T. Urban-biased policies and rising income inequality in China. Am. Econ. Rev. 1999, 89, 306-310. [CrossRef]

9. Ross, C.E.; Mirowsky, J. Refining the association between education and health: The effects of quantity, credential, and selectivity. Demography 1999, 36, 445-460. [CrossRef] [PubMed]

10. Ross, C.E.; Wu, C.L. The links between education and health. Am. Sociol. Rev. 1995, 60, 719-745. [CrossRef]

11. Zhang, X.B.; Kanbur, R. Spatial inequality in education and health care in China. China Econ. Rev. 2005, 16, 189-204. [CrossRef]

12. Hannum, E.; Wang, M. Geography and educational inequality in China. China Econ. Rev. 2006, 17, $253-265$. [CrossRef]

13. Meschi, E.; Scervini, F. A new dataset on educational inequality. Empir. Econ. 2014, 47, 695-716. [CrossRef]

14. Milligan, K.; Moretti, E.; Oreopoulos, P. Does education improve citizenship? Evidence from the United States and the United Kingdom. J. Public Econ. 2004, 88, 1667-1695. [CrossRef]

15. Dee, T.S. Are there civic returns to education? J. Public Econ. 2004, 88, 1697-1720. [CrossRef]

16. Gallego, A. Understanding unequal turnout: Education and voting in comparative perspective. Elect. Stud. 2010, 29, 239-248. [CrossRef]

17. Ministry of Education of the People's Republic of China. Educational Statistics Yearbook of China; China Statistics Press: Beijing, China, 2016.

18. Keng, C.W.K. China's unbalanced economic growth. J. Contemp. China 2006, 15, 183-214. [CrossRef]

19. Zhang, H.F. The poverty trap of education: Education-poverty connections in western China. Int. J. Educ. Dev. 2014, 38, 47-58. [CrossRef]

20. Zhu, Z.Y. Trade-offs between the top-down and bottom-up school education management models the implementation of school development planning in western China. Chin. Educ. Soc. 2008, 41, 36-57. [CrossRef]

21. Liu, M.X.; Murphy, R.; Tao, R.; An, X.H. Education management and performance after rural education finance reform: Evidence from western China. Int. J. Educ. Dev. 2009, 29, 463-473. [CrossRef]

22. Bauer, J.; Wang, F.; Riley, N.E.; Zhao, X.H. Gender inequality in urban China-Education and employment. Mod. China 1992, 18, 333-370. [CrossRef]

23. Gao, Y.; He, Q.S.; Liu, Y.L.; Zhang, L.Y.; Wang, H.F.; Cai, E.X. Imbalance in spatial accessibility to primary and secondary schools in china: Guidance for education sustainability. Sustainability 2016, 8, 1236. [CrossRef]

24. Fennell, S. Why Girls' Education rather than Gender Equality? The Strange Political Economy of PPPs in Pakistan; Edward Elgar: Cheltenham, UK, 2012; pp. 259-276.

25. Shailaja Fennell, M. Gender Education and Equality in a Global Context: Conceptual Frameworks and Policy Perspectives; Routledge: London, UK, 2009; p. 246.

26. Yang, J.; Huang, X.; Liu, X. An analysis of education inequality in China. Int. J. Educ. Dev. 2014, 37, 2-10. [CrossRef]

27. Yu, N.N.; Yu, B.; de Jong, M.; Storm, S. Does inequality in educational attainment matter for China's economic growth? Int. J. Educ. Dev. 2015, 41, 164-173. [CrossRef] 
28. Thomas, V.; Wang, Y.; Fan, X. A New Dataset on Inequality in Education: Gini and Theil Indices of Schooling for 140 Countries 1960-2000; The World Bank: Washington, DC, USA, 2002.

29. Alrasheed, K.; Elgamily, H.I. Gis as an efficient tool to manage educational services and infrastructure in Kuwait. J. Geogr. Inf. Syst. 2013, 1, 75-86.

30. Setyono, D.A.; Cahyono, D.D.; Helmy, M. Measuring service capacity of public facilities based on supply aspect (case study: Elementary school in Malang city). Procedia Soc. Behav. Sci. 2016, 227, 45-51. [CrossRef]

31. Cao, H.H. Spatial inequality in children's schooling in Gansu, western China: Reality and challenges. Can. Geogr./Geogr. Can. 2008, 52, 331-350. [CrossRef]

32. Mei, H.; Jiang, Q.B.; Xiang, Y.Y.; Song, X.P. School consolidation: Whither China's rural education? Asian Soc. Work Policy Rev. 2015, 9, 138-150. [CrossRef]

33. Cotton, K. Affective and Social Benefits of Small-Scale Schooling. Available online: https:/ /www.ericdigests. org/1997-2/small.htm (accessed on 13 February 2018).

34. Lee, V.E.; Smith, J.B. High school size: Which works best and for whom? Educ. Eval. Policy Anal. 1997, 19, 205-227. [CrossRef]

35. Bard, J.; Gardener, C.; Wieland, R. National Rural Education Association Report. Available online: https: / / www.questia.com/library/journal/1P3-1040334711/national-rural-education-association-report-rural (accessed on 13 February 2018).

36. Beeson, E. Rural schools: Facing unique challenges. Principal 2001, 81, 22-24.

37. Zeng, G.H.; Lv, C. Layout adjustment of rural middle and primary school for ten years. Manag. Prim. Second. Schools 2013, 28, 22. (In Chinese)

38. Tao, Q.; Lu, J.Y. Rural small class teaching, the effective ways to promote the balanced development of the urban and rural education. Educ. Theory Pract. 2011, 34, 6. (In Chinese)

39. Yang, D.P. From equality of right to equality of opportunity: The slot of educational equity in new China. Peking Univ. Educ. Rev. 2006, 4, 18.

40. Wan, M.G. To promote education fair and balance development of China's rural education: The potential troubles derived from school consolidation. Educ. Sci. Res. 2009, 25, 19-20.

41. Wu, Q.Q.; Ji, Y.; He, L.P. The problem of the school bus safety. Where is the way out? People's Daily, 11 November $2011 ; 9$.

42. Rao, J.; Ye, J. From a virtuous cycle of rural-urban education to urban-oriented rural basic education in China: An explanation of the failure of China's rural school mapping adjustment policy. J. Rural Stud. 2016, 47, 601-611. [CrossRef]

43. Theil, H. Economics and Information Theory; North Holland Publishing Company: Amsterdam, The Netherlands, 1967.

44. Rayevneva, O.V.; Bobkova, O.Y. Identifying sources of development disparities of Ukraine's regions basing on decomposition of Theil index. Actual Probl. Econ. 2012, 128, 200-210.

45. Feng, C.; Lu, B.; Xu, Z.Q. A weighted Gini coefficient and Theil index-based approach for estimating the spatial disparity in energy efficiency in China. Int. J. Glob. Energy Issues 2016, 39, 4-17. [CrossRef]

46. Borrell, L.N.; Talih, M. A symmetrized Theil index measure of health disparities: An example using dental caries in U.S. Children and adolescents. Stat. Med. 2011, 30, 277-290. [CrossRef] [PubMed]

47. Akita, T. Decomposing regional income inequality in china and Indonesia using two-stage nested Theil decomposition method. Ann. Reg. Sci. 2003, 37, 55-77. [CrossRef]

48. Tan, S.C.; Ho, C.M.; Pang, V. Why has education inequality widened in Sabah, Malaysia? Econ. Bull. 2016, 36, 569-575.

49. Mukhopadhaya, P. Trends in income disparity and equality enhancing (?) education policies in the development stages of Singapore. Int. J. Educ. Dev. 2003, 23, 37-56. [CrossRef]

50. Lin, C.H.A.; Yang, C.H. An analysis of educational inequality in Taiwan after the higher education expansion. Soc. Indic. Res. 2009, 90, 295-305. [CrossRef]

51. Hayashi, M.; Kataoka, M.; Akita, T. Expenditure inequality in Indonesia, 2008-2010: A spatial decomposition analysis and the role of education. Asian Econ. J. 2014, 28, 389-411. [CrossRef]

52. Tsang, M.C. Financial reform of basic education in China. Econ. Educ. Rev. 1996, 15, 423-444. [CrossRef]

53. Tsang, M.C.; Ding, Y.Q. Resource utilization and disparities in compulsory education in China. China Rev. 2005, 5, 1-31. 
54. Li, W.; Park, A.; Wang, S. School Equity in Rural China; Association of Asian Studies: Washington, DC, USA, 2002.

55. Chung, C.; Mason, M. Why do primary school students drop out in poor, rural China? A portrait sketched in a remote mountain village. Int. J. Educ. Dev. 2012, 32, 537-545. [CrossRef]

56. Wang, X.; Liu, C.; Zhang, L.; Luo, R.; Glauben, T.; Shi, Y.; Rozelle, S.; Sharbono, B. What is keeping the poor out of college? Enrollment rates, educational barriers and college matriculation in China. China Agric. Econ. Rev. 2011, 3, 131-149. [CrossRef]

57. Barendsen, R.D. The 1960 educational reforms. China Q. 1960, 4, 55-65. [CrossRef]

58. Greenhalgh, S. Missile science, population science: The origins of China's one-child policy. China Q. 2005, 182, 253-276. [CrossRef]

59. Knight, J.; Gunatilaka, R. Great expectations? The subjective well-being of rural-urban migrants in China. World Dev. 2010, 38, 113-124. [CrossRef]

60. Wong, D.F.K.; Li, C.Y.; Song, H.X. Rural migrant workers in urban China: Living a marginalised life. Int. J. Soc. Welf. 2007, 16, 32-40. [CrossRef]

61. Chen, A. The 1994 tax reform and its impact on China's rural fiscal structure. Mod. China 2008, 34, $303-343$. [CrossRef]

62. Tsang, S.K.; Cheng, Y.S. China tax reforms of 1994-Breakthrough or compromise. Asian Surv. 1994, 34, 769-788.

(C) 2018 by the authors. Licensee MDPI, Basel, Switzerland. This article is an open access article distributed under the terms and conditions of the Creative Commons Attribution (CC BY) license (http:/ / creativecommons.org/licenses/by/4.0/). 